\title{
POLIMORFISMO GENÉTICO DA $\alpha$ S1-CASEÍNA EM CABRAS DO SEMIÁRIDO DO NORDESTE BRASILEIRO
}

\author{
Eleonora de Figueiredo Moraes, ${ }^{1}$ Sildivane Valcácia Silva, ${ }^{2}$ Carlos Adriano Santana Leal, ${ }^{3}$ \\ Laura Leandro da Rocha, ${ }^{4}$ Manoel Adrião Gomes Filho ${ }^{5}$ e Aurea Wischral ${ }^{6}$ \\ 1. Mestre em Ciência Veterinária pela Universidade Federal Rural de Pernambuco. E-mail: eleonorafg@yahoo.com.br \\ 2. Doutoranda da Universidade Federal Rural de Pernambuco \\ 3. Graduação em Medicina Veterinária pela Universidade Federal Rural de Pernambuco \\ 4. Bolsista DTI Instituto Nacional do Semi Árido, Brasil \\ 5. Professor adjunto da Universidade Federal Rural de Pernambuco, Brasil \\ 6. Professora associada da Universidade Federal Rural de Pernambuco, Brasil.
}

RESUMO

\begin{abstract}
A população de raças caprinas naturalizadas e Sem Raça Definida (SRD) do Nordeste do Brasil é pouco caracterizada, apesar da importância que se tem dado aos estudos de recursos genéticos em animais domésticos. Com o objetivo de estudar o polimorfismo do gene da $\alpha$ S1-caseína em DNA genômico de cabras Moxotó e SRD provenientes do Semiárido do Nordeste brasileiro, por meio da técnica de PCR-RFLP (Polymerase Chain Reaction-Restriction Fragment Lenght Polymorfism), foram genotipadas 215 cabras pertencentes aos grupos genéticos Moxotó e SRD, provenientes
\end{abstract}

dos estados de Pernambuco, Paraíba, Rio Grande do Norte e Ceará. Com base na frequência alélica das raças estudadas, não se observou diferença significativa $(p>0,05)$ entre as populações de cada Estado e entre animais Moxotó e SRD. Diante da maior frequência observada do alelo B (forte) do gene da $\alpha \mathrm{S} 1$-caseína nos animais estudados, admite-se a possibilidade de que fenotipicamente esses animais venham a exibir a característica de uma forte produção de proteínas, característica importante para o leite destinado à produção de queijos, favorecendo a caprinocultura da região.

PALAVRAS-CHAVES: DNA, leite, PCR-RFLP.

\section{ABSTRACT}

\section{GENETIC POLYMORPHISM OF THE $\alpha$ S1-CASEIN IN GOATS FROM THE SEMI-ARID OF BRAZILIAN NORTHEAST}

The population of native and mixed-breeds (MB) goats from the Northeast of Brazil is little characterized, despite the importance given to studies of genetic resources in domestic animals. With the objective of studying the polymorphism of the $\alpha \mathrm{S} 1$-casein gene in genomic DNA of Moxoto and mixed-breed goats from the semi-arid of Brazilian Northeast, by the PCR-RFLP (Polymerase Chain Reaction-Restriction Fragment Lenght Polymorfism) technique, 215 Moxotó and mixed-breeed goats, which came from the Brazilian states of Pernambuco, Paraíba, Rio Grande do Norte and
Ceará, were used. Based on the allelic frequency from the breeds studied, there was no significant difference ( $p>0.05)$ among the populations of each studied state and between Moxoto and mixedbreed animals. In face of the detection of a highest presence of allele $\mathrm{B}$ (strong) from the $\alpha \mathrm{S} 1$-casein gene in the animals studied, it is admitted the possibility that, phenotypically, these animals present the characteristic of a strong production of proteins, an important feature for the milk destined to cheese production, favoring the goat raising in the region.

KEYWORDS: DNA, milk, PCR-RFLP. 


\section{INTRODUÇÃO}

A importância econômico-social dos caprinos criados no Nordeste do Brasil reside na produção de leite e de carne, para alimentação das populações de média e baixa renda, como fonte de proteína animal de baixo custo. No entanto, a população das raças caprinas naturalizadas desta região e dos animais Sem Raça Definida (SRD) é pouco caracterizada, apesar da importância que se tem dado aos estudos de recursos genéticos em animais domésticos (SILVA \& ARAÚJO, 2000).

Existem grupos de pesquisadores empenhados em estudar as raças nativas, buscando subsídios para a conservação desse material genético tão importante para a subsistência da população nordestina. No entanto, ainda são poucos os estudos relacionados com as variantes genéticas das caseínas em caprinos no Brasil, destacando-se os trabalhos de MARINI et al. (2007), com cabras Saanen da região Sudeste, e SILVA et al. (2007), com animais da raça Moxotó e Alpina Americana em Pernambuco.

O leite dos ruminantes contém seis proteínas que podem ser classificadas em dois grupos: caseínas $(\alpha \mathrm{S} 1, \alpha \mathrm{S} 2, \beta$ е к) e proteínas do soro ( $\beta$ lactoglobulina e $\alpha$ lactoalbumina). As quatro caseínas são os principais componentes, totalizando $76 \%-86 \%$ do total das proteínas lácteas (MARTIN et al., 2002). A alta concentração de $\alpha \mathrm{S} 1$-caseína parece estar relacionada com a intolerância apresentada por algumas pessoas ao leite bovino, o que tem caracterizado o leite caprino como menos alergênico, por ter uma concentração menor desta caseína (HAENLEIN, 2004). Por outro lado, altos níveis de $\alpha \mathrm{S} 1$ - caseína estão associados a elevado nível de proteína total e micelas menores, contendo menos cálcio, apresentando maior potencial na fabricação de queijos e coalho firme (CLARK \& SHERBON, 2000).

A fração de caseína é codificada por quatro genes ligados e é organizada como um agrupamento em um segmento de DNA genômico de $250 \mathrm{~Kb}$, na seguinte ordem: $\alpha$ S2-caseína (CSN1S2), $\alpha$ S1-caseína (CSN1S1), $\beta$-caseína (CSN2) e K-caseína (CSN3) (THREADGILL \& WOMACK, 1990). O gene CSN1S1 caprino apresenta o maior grau de variabilidade de todos os genes de caseína de ruminantes estudados, e já foram identificados alelos associados com diferentes níveis de expressão de $\alpha \mathrm{S} 1$ - caseína no leite, sendo estes níveis designados "alto", "médio", "baixo" e "nulo" (MARTIN et al., 1999).

A identificação dos alelos da caseína do leite, mediante o emprego da biologia molecular, pode contribuir para o ajuste de programas de melhoramento animal, direcionando o leite produzido para a tecnologia de produtos mais apropriada.

Diante do exposto, objetivou-se caracterizar o genótipo da $\alpha \mathrm{S} 1$-caseína de cabras naturalizadas Moxotó e SRD da Região do Semiárido do Nordeste do Brasil, através da técnica PCR-RFLP (Polymerase Chain Reaction-Restriction Fragment Lenght Polymorfism), para aplicação como ferramenta de seleção quanto à característica do leite, nesses animais.

\section{MATERIAL E MÉTODOS}

\section{Amostras}

Foram utilizadas 215 cabras adultas da raça Moxotó $(\mathrm{n}=126)$ e SRD $(\mathrm{n}=89)$, clinicamente sadias, criadas de maneira extensiva, provenientes da região do Semiárido do Nordeste do Brasil, nos estados do Ceará $(n=51)$, Pernambuco $(n=61)$, Paraíba $(n=77)$ e Rio Grande do Norte $(\mathrm{n}=26)$.

O DNA genômico foi extraído a partir dos leucócitos, através da técnica fenol-clorofórmio modificado (MANIATIS et al., 1989) e estocado a $-20^{\circ} \mathrm{C}$. Realizouse a quantificação do DNA em espectrofotômetro (Bionate 3- ThermoScientífic).

\section{PCR-RFLP da $\alpha$ S1-caseína}

$\mathrm{O}$ éxon nove do gene da $\alpha \mathrm{S} 1$ - caseína foi amplificado usando a Reação de Polimerase em Cadeia (PCR). Desenvolveu-se a reação conforme RAMUNNO et al. (2000).

$\mathrm{O}$ fragmento amplificado com $230 \mathrm{pb}$ foi digerido em volume final de $15 \mu \mathrm{L}$, contendo: $5 \mu \mathrm{L}$ do produto de PCR, $8,4 \mu \mathrm{L}$ de água pura, $1,5 \mu \mathrm{L}$ de tampão da enzima, 1,0 U da enzima XmnI (New England - Biolabs), por quatro horas a $37^{\circ} \mathrm{C}$; em seguida, inativação da enzima a $65^{\circ} \mathrm{C}$ por vinte minutos. Analisaram-se os fragmentos digeridos em gel de agarose $2 \%$ corado com brometo de etídeo.

Os dados foram tratados de forma descritiva, calculando-se a frequência das bandas alélicas encontradas, na forma de percentis (\%), para se estabelecer 
a ocorrência dos alelos encontrados em cada raça e em cada Estado envolvido no estudo. Realizou-se também a verificação das heterozigosidades observadas e esperadas. Assumindo que existe um estado ideal de equilíbrio Hardy-Weinberg (EHW), ele foi verificado utilizando o teste exato de Fischer, que consiste em possíveis frequências genotípicas para um determinado lote de frequências alélicas, rejeitando-se a hipótese de EHW cujas frequências sejam incomuns. O teste exato de Fisher trata do cálculo não enviesado da probabilidade de EHW, usando-se o método em cadeia de Markov, com 1.000 interações (GUO \& THOMPSON, 1992). Utilizou-se a opção excesso de heterozigoto. As análises foram realizadas pelo programa GENEPOP (versão 1.2), sendo o nível de significância padronizado para 0,05 (RAYMOND \& ROUSSET, 1995).

\section{RESULTADOS E DISCUSSÃO}

A amplificação do éxon nove do gene da $\alpha \mathrm{S} 1$-caseína ocorreu em todos os animais estudados apresentando o mesmo padrão com 230 pares de bases $(\mathrm{pb})$. O resultado da digestão enzimática (endonuclease XmnI) produziu dois padrões de fragmentos, sendo duas bandas $(65+165 \mathrm{pb})$ para o alelo B e somente uma banda de 230 pb para o alelo D (Figura 1).

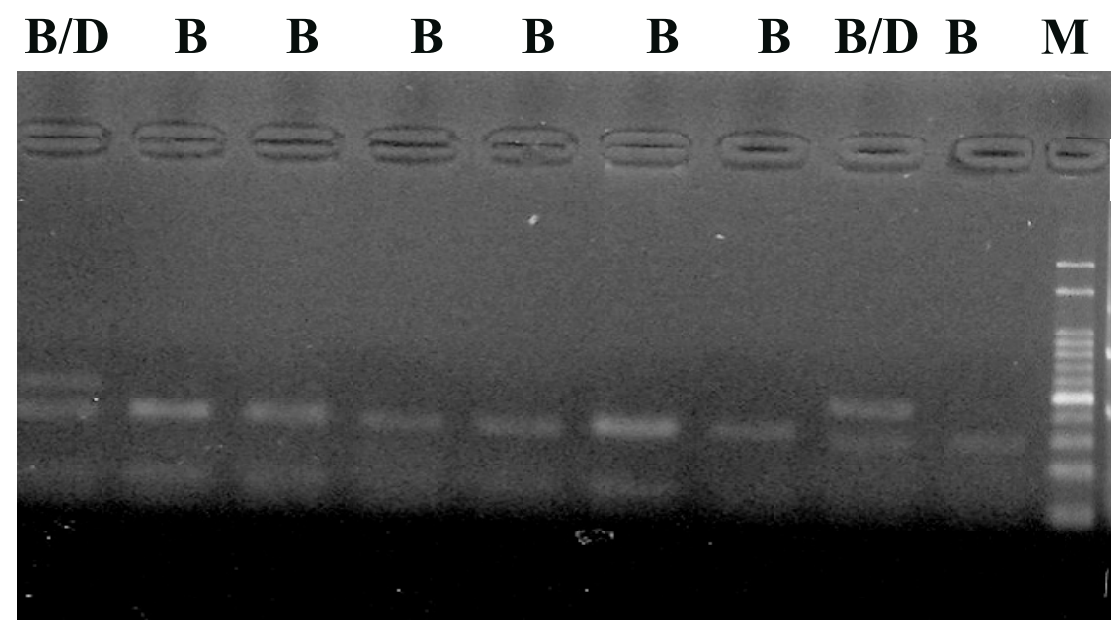

FIGURA 1. Padrão eletroforético obtido por digestão com endonuclease XmnI da região do DNA que contém o gene CSN1S1 na raça Moxotó e SRD nos diferentes estados do Nordeste do Brasil estudados. M: Marcador DNA-Ladder 50 pb.

O gene CSN1S1 caprino apresenta a maior variabilidade de todos os genes de caseína de ruminantes já estudados e até dezesseis alelos são conhecidos nesse lócus (BEVILACQUA et al., 2002). Os dois alelos observados neste trabalho (B e D) já haviam sido relatados por RAMUNO et al. (2000) e SILVA et al. (2007).

Na Tabela 1 encontram-se as frequências alélicas e genotípicas do loco estudado, onde se observou uma maior frequência do alelo $\mathrm{B}$ em relação ao alelo $\mathrm{D}$ em todas as populações estudadas. $\mathrm{O}$ alelo $\mathrm{D}$ é considerado um alelo de nível fraco quanto à produção da proteína no leite, indicando que o leite com baixo teor de caseína é uma importante opção, quando o indivíduo apresenta alergia, se exposto demasiadamente a esse tipo de proteína (MARINI et al., 2007). A predominância do genótipo BB em todas as populações analisadas indica o genótipo característico de maior produção de caseína no leite. De acordo com GROSCLAUDE et al. (1994), os alelos A, B1, B2, B3, B4, C e M (3,6 g/L), H (4,2 g/L) e L (3,6 $\mathrm{g} / \mathrm{L})$ estão relacionados com a elevada presença de $\alpha \mathrm{S} 1$ - caseína no leite. Observou-se baixa frequência de heterozigosidade em todas as populações, principalmente nas populações da Paraíba, Pernambuco e Rio Grande do Norte. A análise das frequências não demonstrou desvios para o EHW seja nas raças ou nos Estados estudados em relação ao loco analisado, 
o que pode ser verificado nos níveis de heterozigoto observados, que apresentaram valores acima quando comparados aos de heterozigotos esperados. Tampouco foi observada diferença significativa entre as proporções de cada raça ou Estado $(\mathrm{P}>0,05)$, não se observando desvios para o EHW (Tabela 1).

$\mathrm{O}$ alelo B da $\alpha \mathrm{S} 1$-caseína foi observado, com maior frequência, na raça nativa francesa Poitevine, embora o alelo E tenha predominado em outros caprinos nativos das montanhas dos Pirineus (Aldudes,
Arette Lourdios, Aspe Pau-Aquitaine, Soulor, Bigorre, Nistos Ariège, Chèvres e Boucs) (RICORDEAU et al., 1996). Do mesmo modo, caprinos indianos apresentaram, pela técnica de PCR /RFLP, alelos A e B em maior proporção (KUMAR et al., 2007). O alelo B (forte) também foi encontrado em maior frequência entre caprinos leiteiros húngaros nativos, do que nas raças importadas, Alpina e Saanen (KUSZA et al., 2007).

TABELA 1. Frequências alélica, genotípica, heterozigosidade observada (Ho) e esperada (He) e o equilíbrio de Hardy Weinberg (EHW) do loco da $\alpha$ S1-caseína na raça Moxotó e SRD nos diferentes estados do Nordeste do Brasil estudados

\begin{tabular}{cccccccc}
\hline \multirow{2}{*}{ Amostra } & \multicolumn{2}{c}{ Alelos } & \multicolumn{2}{c}{ Genótipos } & \multicolumn{2}{c}{ Heterozigozidade } & EWH* \\
\cline { 2 - 8 } & B & D & BB & BD & Ho & He & \\
\hline MCE & 0,932 & 0,068 & 0,8636 & 0,137 & 0,136 & 0,130 & $\mathrm{~ns}$ \\
MPB & 0,985 & 0,015 & 0,969 & 0,031 & 0,030 & 0,030 & $\mathrm{~ns}$ \\
MPE & 0,976 & 0,024 & 0,951 & 0,049 & 0,048 & 0,048 & $\mathrm{~ns}$ \\
MRN & 0,962 & 0,038 & 0,923 & 0,077 & 0,077 & 0,075 & $\mathrm{~ns}$ \\
SCE & 0,931 & 0,069 & 0,862 & 0,138 & 0,138 & 0,130 & $\mathrm{~ns}$ \\
SPB & 0,932 & 0,068 & 0,863 & 0,137 & 0,136 & 0,130 & $\mathrm{~ns}$ \\
SPE & 0,925 & 0,075 & 0,850 & 0,15 & 0,150 & 0,142 & $\mathrm{~ns}$ \\
\hline
\end{tabular}

MCE=Moxotó Ceará; $\mathrm{MPB}=$ Moxotó Paraíba; $\mathrm{MPE}=$ Moxotó Pernambuco; MRN= Moxotó Rio Grande do Norte; $\mathrm{SCE}=\mathrm{SRD}$ Ceará; $\mathrm{SPB}=\mathrm{SRD}$ Paraíba e SPE= SRD Pernambuco; ns= não significativo

* Estatística: Teste exato de Fischer/Nível de significância - 0,05

A concentração total de caseína no leite caprino está positivamente correlacionada com os alelos da $\alpha \mathrm{S} 1$-caseína, sendo maior nos animais que apresentam os alelos A, B e C (GROSCLAUDE et al., 1987).

Não houve um alto polimorfismo na população estudada, sendo verificada uma alta frequência gênica do alelo B. Essa frequência elevada pode sugerir uma proximidade genética desses animais, o que não pode ser confirmado com base nos resultados de apenas um éxon.

SILVA et al. (2007), realizando a genotipagem de cabras criadas no Sertão, Agreste e Zona da Mata do Estado de Pernambuco, constataram que os alelos $\mathrm{B}$ e D foram predominantes para a raça naturalizada Moxotó e animais SRD, e os alelos $\mathrm{C}$ e D, para a raça Alpina Americana, concluindo que existem variações genéticas para o gene da $\alpha \mathrm{S} 1$-caseína do leite das raças caprinas estudadas.
Apesar de ser encontrado, em menor frequência, o alelo D ocorreu nas três populações SRD e em uma Moxotó. Este fato poder ser devido à introdução de outras raças caprinas, que carregam este alelo em sua composição genética como, por exemplo, a Alpina Americana, conforme resultados de SILVA et al. (2007), obtidos pelo mesmo grupo de pesquisa deste trabalho.

Em outro estudo, foi constatado que os genótipos das raças Moxotó e SRD se identificaram com os da raça Canária da Espanha, nas quais os alelos fortes A e B foram mais frequentes (JORDANA et al., 1996).

\section{CONCLUSÕES}

Os resultados demonstraram que não houve um alto polimorfismo nas populações estudadas, sendo verificada maior frequência do alelo $\mathrm{B}$, admitindo-se 
a possibilidade de que fenotipicamente esses animais venham a exibir a característica de uma forte produção de proteínas, característica importante para o leite destinado à produção de queijos, favorecendo a caprinocultura da região.

\section{AGRADECIMENTOS}

À Fundação de Amparo à Pesquisa do Estado de Pernambuco (FACEPE), pelo apoio financeiro, e a Laura Leandro da Rocha, pelo auxílio na análise estatística deste trabalho.

\section{REFERÊNCIAS}

BEVILACQUA, C.; FERRANTI, P.; GARRO, G.; VELTRI, C.; LAGONIGRO, R.; LEROUX, C.; PIETROLA, E.; ADDEO, F.; PILLA, F.; CHIANESE, L.; MARTIN, P. Interallelic recombination is probably responsible for the occurrence of a new as 1 casein variant found in the goat species. European Journal of Biochemistry, v. 269, n. 4, p.1293-1303, 2002.

CLARK, S.; SHERBON, J. W. Genetic variantes of $\alpha_{\mathrm{s} 1}-\mathrm{CN}$ in goat milk: breed distribution and association with milk composition and coagulation properties of goat milk. Small Ruminant Research, v. 38 , n. 2 , p. $135-143,2000$.

GROSCLAUDE, F.; MAHE, M. F.; BRIGNON, G.; DI-STASIO, L.; JEUNET, R. A mendelian polymorphism underlying quantitative variations of goat $\alpha$ s1-casein. Genetics Selection Evolution, v. 19, n.4, p. 399-412, 1987.

GROSCLAUDE, F.; MARTIN, P.; RICORDEAU, G.; REMEUF, F.; VASSAL, L.; BOUILLON, J. Du gène au fromage: le polymorphisme de la caséine $\alpha$-s1 caprine, sés effets, son évolution. Revista de Produção Animal, v. 7, n. 1, p. 3-19, 1994.

GUO, S. W.; THOMPSON, E. A. Performing the exact test of Hardy-Weinberg proportions for multiple alleles. Biometrics, v. 48, p. 361-372, 1992.

HAENLEIN, G. F. W. Goat milk in human nutrion. Small Ruminant Research, v.51, p. 155-163, 2004.

JORDANA, J.; AMILLS, M.; DIAZ, E.; ANGULO, C.; SERRADILLA, J. M.; SANCHEZ, A. Gene frequencies of caprine $\alpha \mathrm{S} 1$ casein polymorphism in Spanish goat breeds. Small Ruminant Research, v. 20, p. 215-221, 1996.

KUMAR, A.; ROUT, P. K.; MANDAL, A.; ROY, R. Identification of the CSN1S1 allele in Indian goats by the PCR-RFLP method. Animal, v. 1, n. 8, p. 1099-1104, 2007.
KUSZA, S.; VERESS, G.; KUKOVICS, S.; JÁVOR, A.; SANCHEZ, A.; ANGIOLILLO, A.; BÓSZE, Z. Technical note: genetic polymorphism of $\alpha \mathrm{S} 1$ and $\alpha \mathrm{S} 2$ caseins in Hungarian Milking Goats. Small Ruminant Research, v. 68, p. 329-332, 2007.

MANIATIS, T.; FRITSCH, E. F; SAMBROOK, J. (Ed.). Molecular cloning: a laboratory manual. New York: Cold Spring Harbor Laboratory Press, 1989. 3 v.

MARINI, S.; SOARES, M. A. M.; RODRIGUES, M. T.; SOMMER, D.; GASPARINO, E.; BRUNO, L. D. G.; SOUZA, A. C.; NAMBA, V. Estudo do alelo G da alpha S1 caseína em uma população de cabras leiteiras. Arquivo de Ciência Veterinária e Zoologia, v. 10, n. 2, p. 105-110, 2007.

MARTIN, P; OLLIVIER-BOUSQUET, M.; GROSCLAUDE, F. Genetic polymorphism of caseins: a tool to investigate casein micelle organization. International Dairy Journal, v. 9, p. 163 $171,1999$.

MARTIN, P.; SZYMANOWSKA, M.; ZWIERZCHOWSKI, L.; LEROUX, C. The impact of genetic polymorphisms on the protein composition of ruminant's milks. Reproduction Nutrion Development, v. 42, p. 433-459, 2002.

RAMUNNO, L.; COSENZA, G.; PAPPALARDO, M.; PASTORE, N.; GALLO, D.; DI GREGORIO, P.; MASINA, P. Identification of the goat CSN1S1 allele by means of PCR-RFLP method. Animal Genetics, v. 31, p. 333-346, 2000.

RAYMOND, M.; ROUSSET, F. GENEPOP (version 1.2): a population genetic softaware for exact tests and ecumeinism. Journal of Hereditarity, v. 86, p. 248-249, 1995.

RICORDEAU, G.; MAHÉ, M. F.; AMIGUES, Y.; GROSCLAUDE, F.; MANFREDI, E. Fréquence dês allèles de la caséine alphas 1 em race Poitevine. Animal Genetic Resources Information, v. 17, p. 103-108. 1996.

SILVA, A. A.; ADRIÃO, M.; JIMENEZ, G. C.; SANTOS, M. C. R.; WISCHRAL, A.; AFONSO, J. A. B. Estudo do polimorfismo genético da $\alpha$ S1 caseína em cabras, no Estado de Pernambuco, Brasil. Acta Scietiarium Animal Sciences, v. 29, n. 3, p. 255259, 2007.

SILVA, F. L. R.; ARAÚJO, A. M. Desempenho produtivo em caprinos Mestiços no Semiárido do Nordeste do Brasil. Revista Brasileira de Zootecnia, v. 29, n. 4, p. 1028-1035, 2000.

THREADGILL, D. W.; WOMACK, J. E. Genomic analysis of the major bovine protein genes. Nucleic Acid Research, v. 18, p. 6935-6942, 1990.

Protocolado em: 4 maio 2009. Aceito em: 25 mar. 2010. 